\title{
Behaviour of UHPFRCs in compression under high stress-rates
}

\author{
Ezio Cadoni ${ }^{1, *}$, Matteo Dotta $^{1}$, and Daniele Forni ${ }^{1}$ \\ ${ }^{1}$ DynaMat Laboratory, University of Applied Sciences of Southern Switzerland, 6952 Canobbio, Switzerland
}

\begin{abstract}
The paper presents the results obtained on cylindrical Ultra High Performance Fibre Reinforced Concrete specimens with diameter of $30 \mathrm{~mm}$ and a height of $60 \mathrm{~mm}$ under compression at high stress rate $(1.7-2.3 \mathrm{TPa} / \mathrm{s})$. Four different percentages of fibre reinforcement are considered $(1,2,3$, and $4 \%$ fibre content) and compared with the results of the matrix (UHPC). A slight reduction of the strength and fracture time with the introduction of fibres is observed. The experimental results are analysed and discussed with the intent to better understand the mechanical behaviour of UHPFRC materials in case of dynamic event under service loading conditions.
\end{abstract}

\section{Introduction}

The innovation of the construction industry has to forcedly pass through the innovation of the building materials. Today, one of the most important challenge is in developing new materials characterized by high strength, high toughness, high durability and possibly able to absorb mechanical energy and last but not least must be cheaper and less energy-consuming than the present materials. Moreover, in the last decades new scenarios have opened due to the increment of manmade actions as terroristic attacks. Severe dynamic actions have to be taken into account for particular constructions such as protective structures, offshore platforms, nuclear waste containers, bridges and any other socially sensitive infrastructures.

Since early nineties Ultra High Performance Fibre Reinforced Concrete (UHPFRC) is one of the most promising material to be used in these cases. In fact, UHPFRC exhibits extraordinary mechanical and durability characteristics in comparison to the traditional concrete. For these reasons, in the frame of a project funded by the Swiss Federal Department of Defence, Civil Protection and Sport, it has been selected as armour material in new shielding elements to protect vulnerable building against improvised explosive devices [1-3].

In order to obtain fundamental information for the designer, a comprehensive investigation into the mechanical properties has been performed on these materials by considering various failure modes (tension, compression, shear) and carrying out a wide experimental campaign.

In this paper the preliminary results on compression tests with a pre-straining state are described. These tests are addressed to know how the presence of a tension state can influence the dynamic response of these materials. In fact, accidental events such as explosion, impact or blast generally act on structures that are usually under service loads which produce a certain level of stresses on the materials. These stresses are combined with those produced by the dynamic event. For a better comprehension of these phenomena it is than necessary that the test specimen was preventively subjected to static (mono-bi-tri-axial) stresses prior to the impact loading.

The experiments have been carried out by means of the uniaxial version of a new machine called 3DModified Hopkinson Bar (3D-MHB). It is a Modified Hopkinson Bar apparatus [4-10] designed to apply dynamic loading in materials having a tri-axial stress state [11]. To study the dynamic response of UHPFRC in compression, in case of an existent pre-straining state, a static value of $56.5 \mathrm{MPa}$ (about $1 / 3$ of the failure stress) has been applied before the dynamic test.

The cylindrical UHPFRC specimens with diameter of $30 \mathrm{~mm}$ and a height of $60 \mathrm{~mm}$ have been tested under compression at high stress rate $(1.7-2.3 \mathrm{TPa} / \mathrm{s})$. Four different percentages of fibre reinforcement have been considered $(1 \%, 2 \%, 3 \%$, and $4 \%$ fibre content) and compared with the results of the matrix (UHPC).

The experimental results are analysed and discussed with the intent to better understand the mechanical behaviour of UHPFRC materials in case of dynamic event under service loading conditions.

\section{UHPFRCs}

The Ultra-High Performance Fibre Reinforced Concretes (UHPFRCs) here analysed are commercial products with four different steel fiber volume fractions $\left(\mathrm{V}_{\mathrm{f}}=1 \%, 2 \%\right.$, $3 \%$ and $4 \%$ ). They are characterized by a very high strength and extremely durable and highly resistant matrix (equivalent water/cement ratio $=0,17$ ). The presence of reinforcement with high carbon straight fibres, $13 \mathrm{~mm}$ long with a diameter of $0.20 \mathrm{~mm}$ (aspect ratio $1 / d$ equal to 65 ) permit to reach very high compression, flexural, and tensile strength. The quasi-

Corresponding author: ezio.cadoni@supsi.ch 
static characterization has been performed in compression with cubic specimens having $100 \mathrm{~mm}$ side and in bending/compression on $40 \times 40 \times 160 \mathrm{~mm}^{3}$ specimens according to EN196. The density values of the composite materials are reported in Table 1; the elastic modulus is $51 \mathrm{GPa}$ and the results of the compression tests after 28 days are reported in Fig. 1.

Table 1. Density of the UHPFRC.

\begin{tabular}{|c|c|}
\hline UHPFRC & $\mathbf{k g} / \mathbf{m}^{\mathbf{3}}$ \\
\hline $1 \%$ & 2362 \\
\hline $2 \%$ & 2414 \\
\hline $3 \%$ & 2473 \\
\hline $4 \%$ & 2549 \\
\hline
\end{tabular}

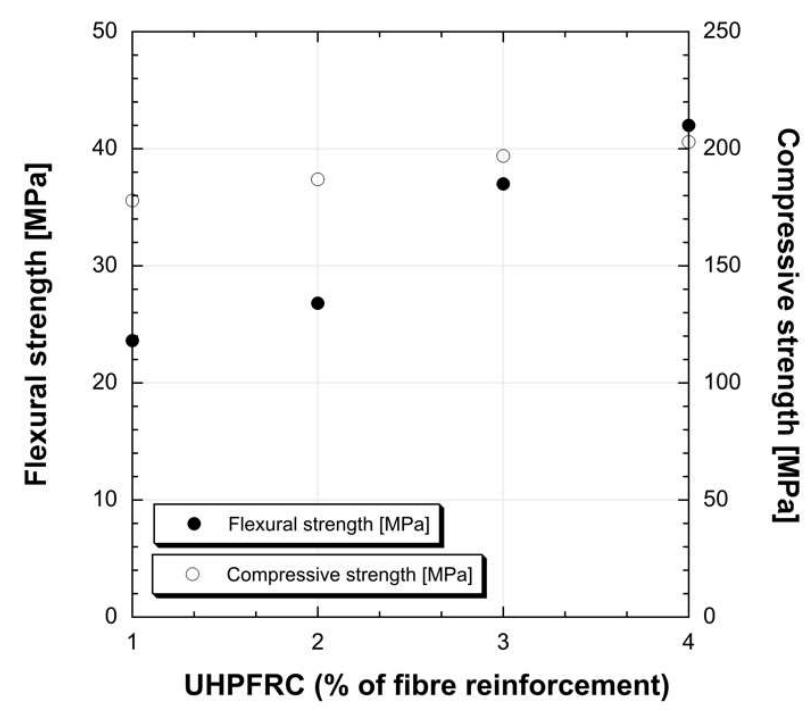

Fig. 1. Flexural and compressive strength of UHPFRC as a function of fiver contain.

\section{Experimental set-up}

The new equipment 3D-MHB (Fig. 2) is installed in the DynaMat Laboratory and consists of a Modified Hopkinson Bar in compression adding a hydraulic actuator at the end of each output bar. In other words, the device permits to obtain a predetermined tri-axial state before the addition of dynamic pulses. As result the five output bars and the input bar will permit to obtain the mechanical response of the materials in this particular condition. The device was designed to analyse the dynamic behaviour of damaged rocks in tri-axial state to understand the massive rock when subject to a wave caused by blast for tunnel excavation or earthquake. At the present, only the first axis has been built and the system acts as a Modified Hopkinson Bar, having pretensioned cylindrical bar, input and output bars of equal length of $2 \mathrm{~m}$ and equal square cross-section of $50 \mathrm{~mm}$ side length. At the end of the output bar is installed the hydraulic actuator to apply the pre-straining in the sample. The machine can generate a rectangular loading pulse of $2 \mathrm{MN}$ amplitude and 800 microsecond duration which propagates through the input bar -specimen output bar deforming the specimen up to fracture.

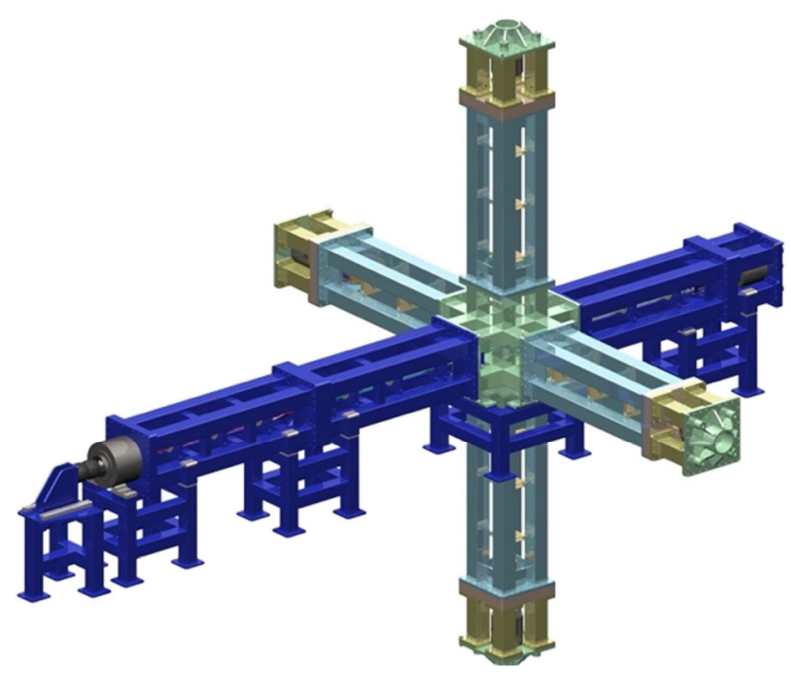

Fig. 2. Scheme of the 3D-MHB device.

In Fig. 3 is shown the scheme of the uniaxial version of the 3D-MHB. It consists of a pre-tensioned bar (cylindrical bar: $\varnothing=56.5, \mathrm{~L}=1750 \mathrm{~mm}$ )), input and output bars (with square cross-section: $50 \mathrm{~mm}$ side; 2200 and $2100 \mathrm{~mm}$ in length, respectively). The total length of the 3D-MHB apparatus along the impact axis is of $7.82 \mathrm{~m}$. The length becomes $8.80 \mathrm{~m}$ when the bumper system is installed. All bars are made of aged maraging steel.

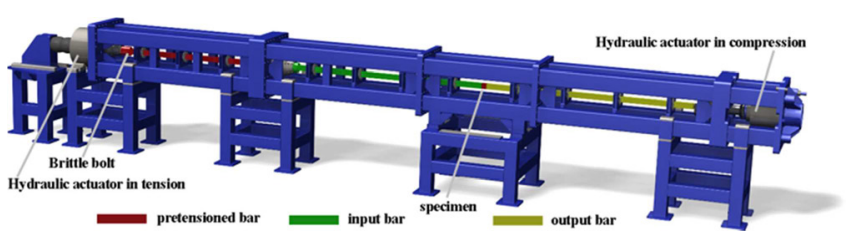

Fig. 3. Uniaxial version of the 3D-MHB device.

The operative sequence to carry out a test using the uniaxial version of 3D-MHB is as follows (refers to Fig. 4). Firstly, a quasi-static stress state in compression is introduced in the UHPFRC specimen by the hydraulic actuator (in compression) placed at the end of the output bar. Secondly, by the principal hydraulic actuator the pre-tensioned bar (in red) is pulled till the established preload value. At this moment, this load is withstanding to the fragile bolt, the pre-tensioned bar and by the contrast ring. Because of the elastic movement of the entire system the pre-load on the specimen have to be checked and ruled by the first actuator. Thirdly, a mechanical system permits to continue to load the bolt without any influence to the rest of the measurement apparatus. In the 3D-MHB, the rupture of the fragile bolt gives rise to a rectangular square pulse propagating to the input bar (green) and output bar (yellow) and dynamically loading the specimen until fracture. Finally, the strain gages on the input and output-confinement bar 
record the incident, reflected and transmitted waves that allow the reconstruction of the equivalent stress-strain curves in the analytical way.

The displacement of the input and output bars are directly measured by means of an electro-optical Extensometer H.-D. Rudolph GmbH (Model 200XR) that permits contactless measurement of the motion of two black-and-white edges (targets) placed on the bars. A high-speed camera IDT Y4-S3 Motion Pro Camera has been used for the fracture process during the test. A typical set-up is shown in Fig. 4.

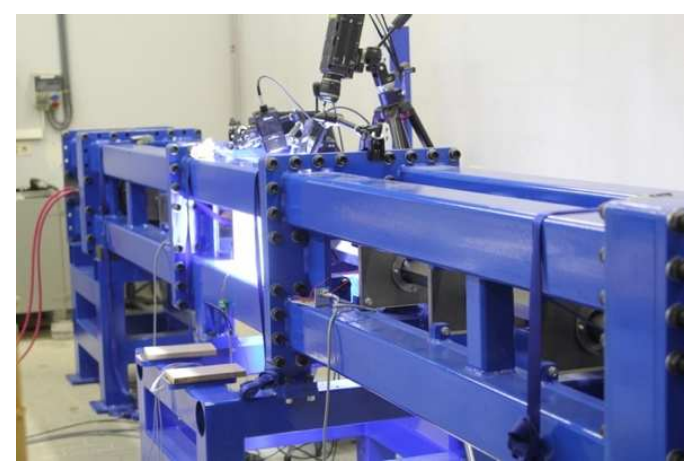

Fig. 4. Uniaxial version of the 3D-MHB set-up.

\section{Results}

The first experimental campaigns were addressed to compare four different UHPFRCs and their matrix UHPC with the same stress rate condition and same geometry.

A pre-straining in compression has been imposed, in particular a pre-compression state of $40 \mathrm{kN}(56.6 \mathrm{MPa}$, corresponding to usual service load) has been applied. This is important for the understanding of the material behaviour in case of dynamic event under service loading conditions.

In Table 2 are reported the results obtained on cylindrical UHPC specimens with diameter of $30 \mathrm{~mm}$ and a height of $60 \mathrm{~mm}$. Four different percentages of fibre reinforcement have been considered and compared with the results of the matrix (UHPC). It has been observed a slight reduction of the strength and fracture time with the introduction of fibres. The fibres act as discontinuities in the matrix and induce micro-cracking propagation but successively they help the post-peak behaviour acting as bridge between the two mouths of the crack, keeping them connected together. In Fig. 6 is shown the comparison of the sequence of images during the dynamic tests (28'300 fps).

Incrementing the diameter of the brittle bolt (Fig. 9) in the 3D-MHB is possible to increase both the preload in the pre-tensioned bar and the test velocity. In Fig. 10 the stress versus time curves of the $60 \mathrm{~mm}$ long specimens are shown. In this case the post-peak disappears and the failure mode pass from the classical prismatic path in compression to the shear mode. The strength does not change.
Table 2. Results on specimens ( $\mathrm{D}=30 \mathrm{~mm}, \mathrm{H}=60 \mathrm{~mm})$.

\begin{tabular}{|c|c|c|c|}
\hline Material & $\begin{array}{c}\text { Stress Rate } \\
{[\mathrm{GPa} / \mathrm{s}]}\end{array}$ & $\begin{array}{c}\text { Stress } \\
{[\mathrm{MPa}]}\end{array}$ & $\begin{array}{c}\text { Fracture time } \\
{[\mu \mathrm{s}]}\end{array}$ \\
\hline UHPC_0\% & $\begin{array}{c}1431 \\
(155)\end{array}$ & $\begin{array}{c}588 \\
(15)\end{array}$ & $\begin{array}{l}395 \\
(14)\end{array}$ \\
\hline \multirow{2}{*}{ UHPFRC_1\% } & $\begin{array}{c}1589 \\
(151)\end{array}$ & $\begin{array}{c}550 \\
(25)\end{array}$ & $\begin{array}{l}319 \\
(45)\end{array}$ \\
\hline \multirow{2}{*}{ UHPFRC_2\% } & $\begin{array}{c}1666 \\
(48)\end{array}$ & $\begin{array}{c}572 \\
(20)\end{array}$ & $\begin{array}{l}357 \\
(38)\end{array}$ \\
\hline \multirow{2}{*}{ UHPFRC_3\% } & $\begin{array}{c}1557 \\
(117)\end{array}$ & $\begin{array}{c}562 \\
(10)\end{array}$ & 354 \\
& 1437 & 579 & 372 \\
\multirow{2}{*}{ UHPFRC_4\% } & $(7)$ & $(16)$ & $(32)$ \\
\hline
\end{tabular}
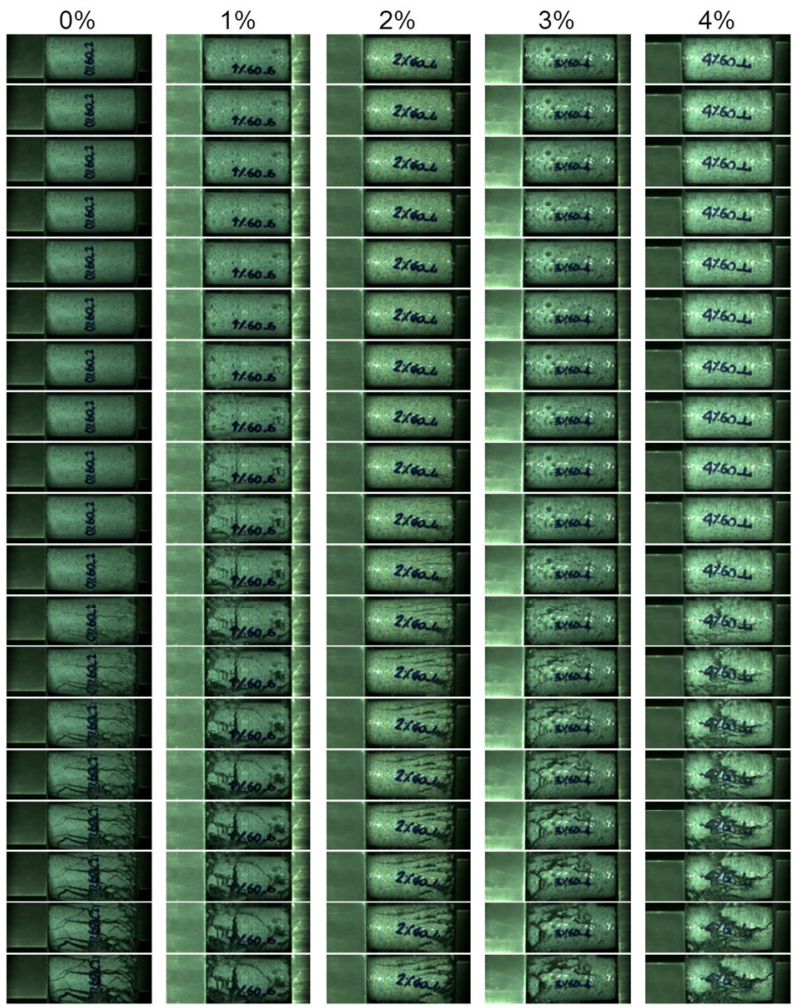

Fig. 5. Sequence of the images for the 5 materials.

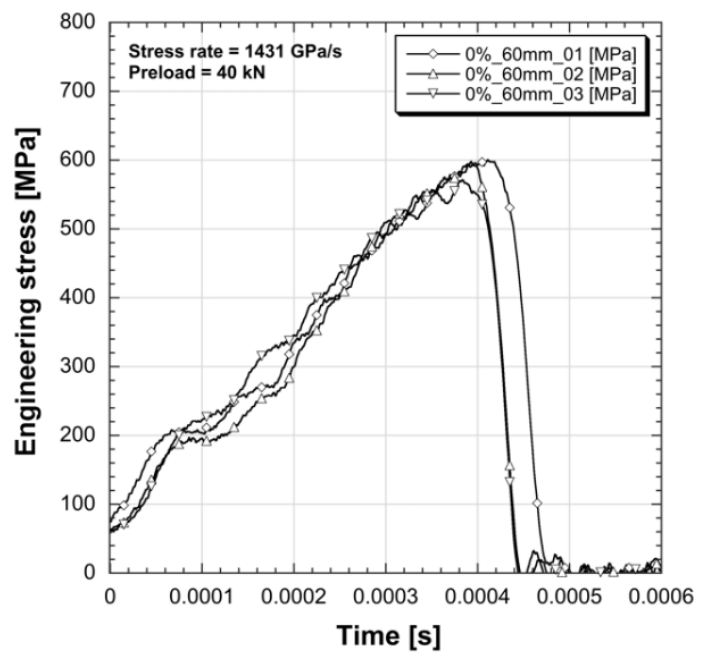

Fig. 6. Stress vs. time curves of the UHPC $(60 \mathrm{~mm})$. 


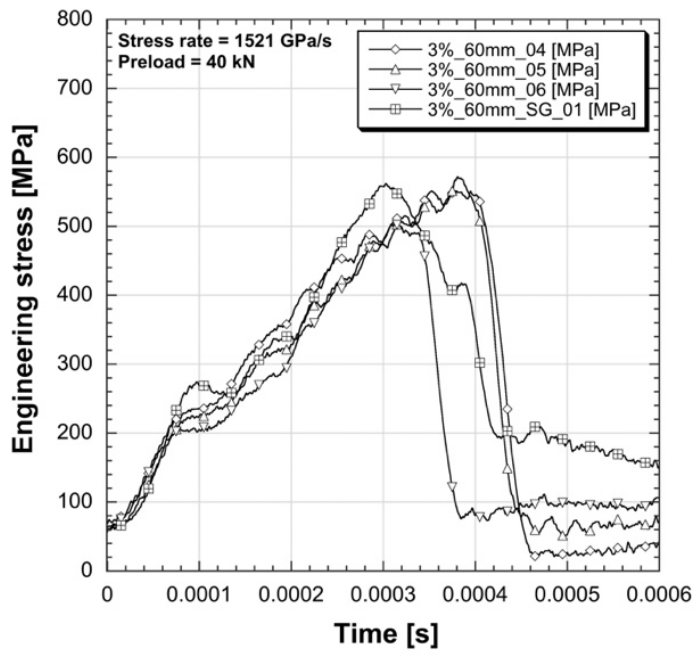

Fig. 7. Stress vs. time curves of the UHPFRC 3\% (60 mm).

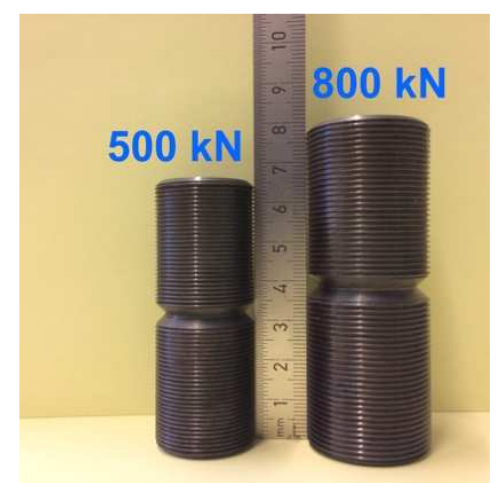

Fig. 8. Bolts used for the two testing conditions.

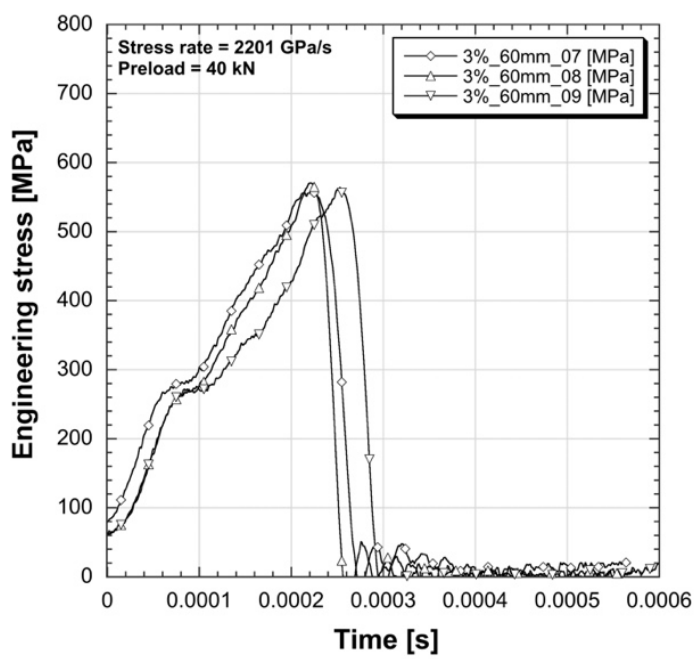

Fig. 9. Stress vs. time curves of the UHPFRC 3\% with $800 \mathrm{kN}$ preload.

\section{Concluding remarks}

To analyse the dynamic behaviour of UHPFRC material in pre-confined conditions has been used a new facility named 3D-MHB in the uniaxial version.
Contrarily to concrete, that exhibits a noticeable strain rate sensitivity in tension and compression $[2,3,12]$, UHPFRCs show a lower sensitivity. According to the present study the fiber volume content does not contribute to the enhancement of the strength capacity and has no significant effect on the strain-rate sensitivity [13]. Incrementing furtherly the stress-rate it has been observed the disappear of the post-peak strength caused by the probable change of failure mechanism.

The material strength is not incremented with increasing of stress rate. This fact can be attributed to the saturation of the capacity of these materials in their ability to create new fractures. In fact, the higher is the stress rate the higher is the fragmentation level, i.e. the dimension of the residual pieces are more and more lower with increasing the velocity, with growing percentages of powder obtained.

Many other parameters must be taken into account to understand the dynamic behaviour of these materials. The fibre orientation plays a capital role both in tension [14] and compression. The compressive strength seems governed essentially by the matrix strength while the fibre bridging capacity is fundamental for the post-peak behaviour and for the strain-hardening capacity when permitted.

By incrementing the stress rate has not been observed an enhancement in terms of strength, that means that the dynamic increase factor is limited. This is reasonable because in other case an infinity strength could be hypothesized. The further researches will be addressed to a new approach based on the energy flow that consider the total energy balance of the material.

This work has been supported by armasuisse - Science and Technology of the Swiss Federal Department of Defence, Civil Protection and Sport.

\section{References}

1. E. Cadoni, On the mechanical characterization of materials for Protection of Infrastructure Elements from the effects of IEDs, in 'Response of Structures Under Extreme Loading', DEStech, 44-51. (2015)

2. E. Cadoni, D. Forni, EPJ-ST 225(2), 253-264 (2016)

3. A. Bragov, A. Konstantinov, A. Lomunov, D. Forni, G. Riganti, E. Cadoni, EPJ WoC 94, 01020 (2015).

4. E. Cadoni, C. Albertini, G. Solomos, J. de Phys. IV 134, 647-652 (2006)

5. E. Cadoni, G. Solomos, C. Albertini, Mag. Concr. Res. 61(3), 221-230 (2009)

6. E. Cadoni, G. Solomos, C. Albertini, Mag. Conc. Res. 65(11), 660-672 (2013)

7. D. Asprone, E. Cadoni, F. Iucolano, A. Prota , Cem. Conc. Comp. 53(10), 52-58. (2014)

8. D. Asprone, E. Cadoni, A. Prota , G. Manfredi, ASCE J. Comp. Constr. 13(6), 558-564 (2009)

9. L. Coppola, E. Cadoni, D. Forni, A. Buoso, Appl. Mech. Mat. 82, 190-195 (2011)

10. L. Fenu, D. Forni, E. Cadoni, Comp. Part B: Engg 92(5) 142 - 150 (2016) 
11. E. Cadoni, M. Dotta, D. Forni, G. Riganti, C. Albertini, EPJ WoC 9401031 (2015).

12. Z. Rong, W. Sun, Y. Zhang, Int. J. Imp. Engg 37 515-520 (2010)

13. D. Yoo, N. Banthia, Cem. Conc. Comp. 73 267-280 (2016)

14. B. Luccioni,F. Isla, D. Forni, E. Cadoni, Mecc. Comput. XXXIV 199-223 (2016) 
